\title{
Psicologia escolar e gestão democrática: atuação em escolas públicas de Educação Infantil
}

\author{
Julia Chamusca Chagas \\ Regina Lúcia Sucupira Pedroza
}

\begin{abstract}
Resumo
Este trabalho parte da experiência de uma das autoras como psicóloga escolar de uma Associação Pró-Educação do Plano Piloto do DF. Com base na Constituição Federal, que estabelece a gestão democrática como princípio para o ensino público, objetivamos construir uma proposta de atuação do psicólogo escolar para a gestão democrática em escolas públicas de Educação Infantil. A pesquisa consistiu de dois momentos: (1) entrevistas com 3 ex-psicólogas da Associação e produção de relato de vivência profissional da pesquisadora; (2) entrevistas com 17 gestores e 2 psicólogas das escolas públicas de Educação Infantil do Plano Piloto do DF e com uma coordenadora regional do serviço de psicologia. Defendese uma atuação cotidiana do psicólogo junto aos membros da escola em diferentes ações, tais como: construção do projeto político pedagógico, mediação das relações interpessoais, escuta dos não ditos nos diálogos, olhar diferenciado para a singularidade dos sujeitos e compreensão da diversidade do desenvolvimento humano.
\end{abstract}

Palavras-chave: Psicologia escolar, educação infantil, gestão democrática.

\section{School psychology and democratic management: working at children's education public schools}

\begin{abstract}
This study comes from one of the author's professional experience as school psychologist at a Pro-education Association in Plano Piloto (Brasilia). Considering that the Federal Constitution establishes the democratic management as a principle for public education, our goal was to create a proposal for the school psychologist's work towards the democratic management of public Infant Education schools. The research was conducted in two phases: (1) interviews with three of the Association's former school psychologists and a report of professional experience produced by the researcher; (2) interviews with seventeen managers and two psychologists from public Infant Education schools and with a regional coordinator of the psychology service. We argue that the school psychologist's role must be to work alongside the school members participating in their routine with different actions, such as: constructing the political and pedagogical project, mediating interpersonal relations, listening to the unspoken in the school's communication, offering a different view to individuals' uniqueness and understanding the diversity of human development.
\end{abstract}

Keywords: School psychology, early childhood education, democratic management.

\section{Psicología escolar y gestión democrática: actuación en escuelas públicas de educación infantil}

\section{Resumen}

Este trabajo parte de la experiencia de una de las autoras como psicóloga escolar de una Asociación Pro-Educación del Plan Piloto del Distrito Federal (DF). Basados en la Constitución Federal que establece la gestión democrática como principio de la enseñanza pública se tiene el objetivo de construir una propuesta de actuación del psicólogo escolar para la gestión democrática en escuelas públicas de Educación Infantil. La investigación se constituye de dos momentos: (1) entrevistas con 3 ex-psicólogas de la Asociación y producción de relato de vivencia profesional de la investigadora; (2) entrevistas con 17 gestores y 2 psicólogas de las escuelas públicas de Educación Infantil del Plano Piloto del DF y con una coordinadora regional del servicio de psicología. Se defiende una actuación cotidiana del psicólogo junto a los miembros de la escuela en diferentes acciones tales como: construcción del Proyecto Político Pedagógico, mediación de las relaciones interpersonales, escuchar "lo no dicho" en los diálogos, mirada diferenciada para la singularidad de los sujetos y comprensión de la diversidad del desarrollo humano.

Palabras Clave: Psicología Escolar, Educación Infantil, gestión democrática. 


\section{Introdução}

A relação entre Educação e Psicologia se constituiu ao longo da história de maneira delicada e muitas vezes problemática. Segundo Wallon (1937/1979), essa relação foi frequentemente assimétrica ao colocar a Psicologia no lugar de normatizadora da prática pedagógica. Entretanto, o autor, ao definir o objeto da psicologia como o ser humano concreto, em constante desenvolvimento, enquanto produto e produtor da sua história, concebe essa relação como mais simétrica. Para ele, psicologia e educação são inseparáveis e contribuem mutuamente entre si.

A psicologia escolar, constituída no bojo dessas complexas relações entre as duas áreas, surge com o objetivo de ressaltar a importância de o psicólogo atuar mais próximo da escola e de se referir a esse contexto específico. Entretanto, a entrada dessa ciência na escola serviu, em um primeiro momento, à seleção e à adaptação dos educandos a um modelo social, reproduzindo na escola a formação de uma sociedade de classes, em um claro compromisso ideológico com a manutenção do status quo. A psicologia escolar se constituiu, portanto, nesse contexto, com intenção de fornecer justificativas legitimadoras de uma escola excludente (Patto, 1987).

Vários são os trabalhos de psicologia escolar que se iniciam com uma crítica ao chamado modelo clínico de atuação. Essas críticas baseiam-se no entendimento de que essa atuação foca-se nos problemas escolares como resultado de patologias presentes nos alunos, diagnosticadas por testes e tratadas por psicoterapia. É uma concepção de atuação reducionista que localiza nas diferenças entre os indivíduos as razões do seu insucesso. Estudos feitos na década de 80, como o de Andaló (1984), mostram que essa atuação fundamenta-se na lógica saúde versus doença para avaliar os problemas psíquicos, escondendo as possíveis influências dos aspectos pedagógicos ou das relações constituídas no contexto escolar que influenciam esse processo. Dessa forma, baseia-se na culpabilização, desconsiderando toda complexidade do sistema educacional, que envolve fatores múltiplos que vão além dos psicológicos.

Para Patto (1987), quando o psicólogo localiza as causas de um problema da escola apenas no psiquismo ou em aspectos cognitivos dos alunos, ele auxilia a manutenção de uma escola sabidamente excludente e coloca-se a serviço dela. Esse tipo de atuação reflete uma concepção de educação para a uniformidade, o adaptacionismo e o silenciamento dos conflitos no ambiente escolar.

Essas críticas ao modelo clínico e à produção do fracasso escolar abriram espaço para a construção de novas possibilidades para a área. Essa construção demanda novos modelos teórico-metodológicos que permitam um estudo dos fenômenos educacionais a partir dos processos que ocorrem no contexto escolar, superando a concepção de que apenas a criança tem que se adaptar à escola (Souza, 2009). Ressalta-se a necessidade de se conceber o cotidiano e os conflitos escolares sob um novo paradigma, que compreenda o processo educativo e o desenvolvimento humano em sua totalidade, sem reducionismos e sem uma causalidade linear, superando, assim, a visão médica do modelo clínico.

Souza (2009) aponta o crescimento da corrente crítica de psicologia escolar nos últimos anos, por meio de trabalhos que buscam: superar a responsabilização dos alunos e suas famílias pelos problemas da escola; formular novos instrumentos e práticas de avaliação psicológica e de entendimento da queixa escolar; e promover ações de formação de professores e profissionais de saúde. Cada vez mais se enxerga a escola como espaço de constituição de sujeitos, cumprindo políticas educacionais estabelecidas pelos interesses da sociedade. Ampliam-se os espaços de atuação para além da escola formal: em projetos sociais para diversos grupos etários, ações de promoção de saúde, organizações governamentais e não governamentais. Esses novos espaços de atuação relacionam-se com o aumento da participação do psicólogo em políticas públicas e com a importância que o trabalho pelos direitos humanos tem conquistado na área. Nesse sentido, a psicologia escolar volta-se para a construção de uma educação de qualidade e de uma escola mais democrática.

A partir dessa reflexão, propõem-se novos modelos de atuação do psicólogo na escola. O compromisso do psicólogo passa a ser o da transformação da realidade escolar e social e não o ajustamento à escola de crianças ditas desviantes (Patto, 1987). Para Meira (2003), é necessário realizar um trabalho mais responsável e comprometido com a sociedade, contribuindo para o fenômeno de a educação constituir-se em objeto possível da ação humana transformadora. Essa autora afirma, também, que é papel do psicólogo escolar auxiliar a construção de uma gestão escolar democrática e ampliar a participação da comunidade na escola.

Nesse sentido, a proposta pedagógica precisa ser pensada como articulada à estrutura administrativa e política da escola e à visão crítica da sociedade em que se insere. Construir e manter uma escola democrática, autônoma e de qualidade é o ideal para a formação de cidadãos críticos, participativos e aptos a problematizar o mundo à sua volta. Esse tipo de educação demanda a participação de todos os atores do contexto escolar no sentido de discutir os seus objetivos em relação ao projeto educativo e interferir no processo de gestão escolar de uma maneira mais ampla e impactante.

Dessa forma, estudos sobre a importância da gestão democrática das escolas públicas e a maneira como esse tipo de gestão tem se efetivado atualmente ganham relevância no contexto de uma psicologia escolar comprometida com uma escola democrática. Torna-se essencial enfatizar a autonomia das escolas e da construção coletiva do processo educativo como transformação social. Por meio da gestão democrática, cada comunidade politicamente organizada participa ativamente da construção do projeto político pedagógico para servir às necessidades da sua própria comunidade e refletir criticamente sobre a sua história e realidade (Freire, 2000).

A gestão democrática está estabelecida na Constituição Federal (1988) como princípio para o ensino nas escolas públicas. A Lei de Diretrizes e Bases da Educação Nacional 
(LDB) também aborda essa questão ao definir como normas a participação dos profissionais da educação na elaboração do projeto pedagógico, assim como das comunidades escolar e local em conselhos escolares ou equivalentes. A partir desses fundamentos legais, são dadas as bases para a construção coletiva do projeto político pedagógico (PPP) das escolas com a participação de todos os seus membros.

Entretanto, o conceito de gestão democrática é parte de um todo condicionado por fatores políticos, econômicos e socioculturais que marcam a sua definição. Apesar de seus fundamentos legais terem partido de lutas de educadores e setores populares da sociedade, esse tipo de gestão assume características diversas no jogo político de interesses de diferentes setores da população (Peixoto, 2009). A apropriação neoliberal, com sua perspectiva de diminuição da responsabilidade do Estado pela educação pública, define esse princípio como descentralização, mas limita a autonomia das escolas por meio da regulação, do controle e da avaliação. Já a concepção progressista, principalmente baseada na produção de Paulo Freire, busca a participação ativa da comunidade a fim de promover uma escola autônoma e uma educação emancipadora, porém mantendo a responsabilidade do Estado (Barreto, 2007).

A fim de contribuir para esse cenário, este estudo partiu da experiência profissional de uma das autoras como psicóloga escolar de uma escola de Educação Infantil do DF que é uma Associação Pró-Educação. Isso nos remete a uma discussão sobre o conceito de infância, seu caráter histórico e social e a maneira como essa etapa educacional é planejada a partir desse conceito. Assim, encontramos nas teorias de Vigotski e Wallon as bases para estudar as especificidades do desenvolvimento da criança de zero a cinco anos, dentro de uma concepção calcada no materialismo dialético. A criança é vista por inteiro, em uma unidade que mantém contradições e movimentos constantes. Esses autores consideram o estudo do desenvolvimento da criança real, concreta, da forma como se apresenta, em uma unidade indissolúvel entre o indivíduo e a sociedade. $\mathrm{O}$ desenvolvimento, assim, não é uniforme. É dialético, feito de oposições e de identificações (Pedroza, 2003). Buscamos fundamento ainda em Larosa (2004) e em Castro (2001) em suas semelhantes críticas às questões ideológicas presentes na concepção de infância como algo natural e universal. Na reflexão desses autores, questiona-se a busca por previsibilidade sobre o desenvolvimento infantil com o fim de controlá-lo, o que legitima o poder dos adultos sobre as crianças e retira delas os seus direitos e a sua autonomia. As elaborações desses autores abrem possibilidades para uma educação que realmente esteja aberta a conhecer a criança como ela se apresenta, questionando o que supostamente já sabe sobre ela e tomando-a como um outro que pode se apresentar da maneira como for.

Essa escola é uma associação de pais, professores e funcionários, sem fins lucrativos, fundada nos anos 80 por pais insatisfeitos tanto com a educação pública quanto com a particular no DF. Esse grupo organizou-se de forma a garantir o acesso, a participação e a decisão igualitária e democrática de todos os associados no cotidiano da escola (Pulino, 2001). Essa visão da comunidade escolar como uma comunidade educativa considera todos os indivíduos envolvidos como educandos e educadores. Cada membro pode apresentar a sua colaboração ao processo educativo e aprender a construir uma escola ao longo de assembleias, reuniões e debates. Isso implica que pais e funcionários não serão apenas clientes ou empregados, mas sim membros ativos da reflexão e prática educativas. Nesse contexto, o trabalho do psicólogo escolar também envolve uma reflexão constante sobre esse modelo de educação a fim de apreender a sua complexidade.

Para compreender os movimentos que os associados realizam para construir e reconstruir diariamente o seu PPP, torna-se necessário aliar o conhecimento amplo da instituição, dentro de seu contexto sócio-histórico, ao entendimento da dinâmica subjetiva dos indivíduos e das suas relações interpessoais. Assim, essa é uma experiência de atuação em psicologia escolar alinhada com as novas perspectivas da área e com a busca por um papel que assuma o compromisso ético-político com a transformação do sistema educacional. As peculiaridades desse contexto trazem à tona demandas específicas que podem produzir um arcabouço teórico que auxilie a elaboração da atuação do psicólogo na gestão democrática, que pode ser estendida a escolas públicas.

Os objetivos desta pesquisa foram: 1) analisar o papel do psicólogo escolar na Associação Pró-Educação no processo de gestão democrática; 2) investigar o trabalho do psicólogo escolar na gestão democrática das escolas públicas de Educação Infantil do Plano Piloto do DF; e 3) construir uma proposta de atuação do psicólogo escolar para a gestão democrática nas escolas públicas de Educação Infantil.

\section{Método}

A ciência como uma prática engajada com compromisso social ressalta que a produção de conhecimento não pode prescindir da reflexão política. O materialismo dialético fornece bases para desenvolver uma metodologia para a psicologia que busque respostas efetivas para os problemas sociais, a partir de uma concepção de ser humano concreto, produto e produtor de sua história (Vigotski, 1931/2000; Wallon, 1951/1975). Esse compromisso é contemplado neste estudo, que busca contribuições da psicologia para a efetivação do direito constitucional de todos os membros da escola participarem ativamente no seu processo de gestão.

A pesquisa consistiu de dois momentos: 1- investigação do papel do psicólogo escolar na Associação Pró-Educação e 2- levantamento da atuação desse profissional nas escolas públicas de Educação Infantil do Plano Piloto (DF). No primeiro, foram entrevistadas as três ex-psicólogas escolares da associação que atuaram imediatamente antes da autora, a fim de investigar o papel do psicólogo escolar nessa escola em diferentes momentos da sua história e compreender que ações elas realizaram para constituir e 
manter o processo de gestão democrática. Além disso, foi produzido um relato da vivência profissional dessa autora como psicóloga escolar dessa associação, a fim de evidenciar a importância do saber oriundo da experiência vivida no exercício profissional.

No segundo momento, foram entrevistados 17 gestores (dois vice-diretores, quatro coordenadores pedagógicos e 11 supervisores pedagógicos) de 15 escolas públicas de Educação Infantil do Plano Piloto do DF com objetivo de conhecer como tem sido pensada e implementada a gestão democrática nessas instituições; sobre o papel do psicólogo escolar. Foram entrevistadas, ainda, duas psicólogas que compõem Equipes Especializadas de Apoio à Aprendizagem (EEAAs) e trabalham em salas próprias que se localizam em duas escolas de Educação Infantil. A fim de compreender melhor como essas equipes são formadas e idealizadas, foi entrevistada também a Coordenadora Intermediária do Serviço Especializado de Apoio à Aprendizagem da Diretoria Regional de Ensino do Plano Piloto (daqui em diante chamada de Coordenadora do SEAA), responsável pela coordenação das equipes na região. Foi consultada, ainda, a Orientação Pedagógica desse serviço, OP-SEAA (Secretaria de Estado de Educação do Distrito Federal, 2010), que traz as diretrizes e a normatização do trabalho das EEAAs junto às escolas do DF.

Ao final, o material das entrevistas e do relato de vivência profissional foi transcrito e agrupado em blocos de acordo com o tema e a semelhança das respostas.

\section{Resultados e Discussão}

\section{Primeiro Momento: Associação Pró-Educação}

As entrevistas com as três ex-psicólogas da associação e o relato da vivência profissional da autora ofereceram uma compreensão mais ampla dessa escola, das mudanças pelas quais passou, da sua organização associativa, da maneira como participam seus vários membros e do papel do psicólogo frente a todos esses elementos no processo de gestão democrática. Enfatizaram, ainda, a relevância desse projeto associativo como uma oportunidade de exercício democrático diário e o seu impacto nos sujeitos que por ela passam.

Essas falas permitem realizar uma caracterização do trabalho do psicólogo escolar nesse contexto, refletir sobre as suas ações e perceber a importância do seu trabalho junto aos diversos membros da escola na construção de uma educação democrática. O papel do psicólogo escolar se construiu ao longo da história da associação de forma intrinsecamente ligada à sua constituição democrática. Percebemos, portanto, como elemento essencial dessa atuação a compreensão da necessidade de participação de todos na construção cotidiana do seu PPP. As informações obtidas ajudam a detalhar as ações que realizavam no cotidiano para o processo de gestão democrática.

\section{1: Gestão democrática da associação e a atuação do psicólogo escolar}

Nas três entrevistas e no relato, ficou evidenciada a visão da experiência associativa como a maior riqueza dessa escola. As participantes retomam em vários momentos das suas falas a importância da construção democrática coletiva, do impacto dessa experiência na vida das pessoas e da sua atuação nesse processo. Ela envolve um engajamento e compreensão do jogo democrático, fornecendo um olhar para o respeito à forma de cada pessoa participar; contempla, também, a busca por parcerias no cotidiano da escola, entendendo como importante a contribuição de todos para que o PPP permaneça dinâmico frente às novas realidades e necessidades; engloba, por fim, a mediação das relações interpessoais, reconhecendo a importância dos conflitos como promotores do desenvolvimento e contribuindo para a construção de espaços de diálogo e respeito à diversidade dos sujeitos em sua forma de ser no mundo. A atuação do psicólogo escolar, portanto, demanda ações dirigidas a cada membro da escola, contemplando todos os segmentos que a compõem: pais, professores, funcionários e alunos.

\section{a) Atuação das psicólogas escolares junto aos pais}

Em cada espaço de diálogo com os pais, desde os atendimentos individuais até as grandes reuniões, a ação das psicólogas se dava no sentido de criar novas possibilidades de participação para todos, contemplando a sua singularidade. Ao mesmo tempo em que é necessário desenvolver uma compreensão sobre essas possibilidades, sem condenar ou denegrir ninguém por escolher ausentar-se do processo, é também de fundamental importância buscar ações que estimulem a participação, criando espaços para que todos possam se colocar e se posicionar. Essas ações passam por contradições, aliando o acolhimento e a compreensão ao estímulo e à responsabilização de todos.

\section{b) Atuação das psicólogas escolares junto aos professores}

Percebe-se pelas entrevistas e pelo relato que o maior foco de atuação dos psicólogos escolares junto aos educadores da associação é a formação de professores. Essa formação denota a importância de a psicologia contribuir para a construção de um olhar para a criança no sentido de compreender o seu desenvolvimento, quais as questões que o professor precisa ter atenção e de como respeitar o ritmo de cada um ao mesmo tempo em que busca estimular esse desenvolvimento. Enfatiza-se o cuidado com cada criança e a tentativa de compreender o que ela diz com as suas ações.

Essa formação contempla, ainda, uma preocupação constante com a formação da pessoa do professor (Pedroza, 2003). Essa compreensão passa pelo reconhecimento das limitações pessoais com cada criança ou situação, o que demanda criar possibilidades para que esse professor 
desenvolva a sua sensibilidade, humildade e amorosidade na sua prática. O papel do psicólogo escolar, portanto, não pode prescindir da escuta clínica, de uma forma diferenciada de acolher as pessoas e de respeito aos limites de cada um. Ele atua na compreensão de como cada professor percebe a sua prática juntamente com a participação democrática e que significados cria a partir dos conflitos cotidianos. A atenção à maneira como cada professor, dada a sua subjetividade, entende o seu papel no processo educativo democrático é fundamental nesse processo de formação.

\section{c) Atuação das psicólogas escolares junto aos funcionários}

As psicólogas ressaltaram a importância da atuação junto aos funcionários no sentido de valorizá-los como educadores, tentando construir um novo sentido social para a sua função. Essa é uma categoria cujo trabalho, em uma sociedade de classes, é desqualificado frente à importância que é dada à educação como forma de ascensão profissional e, consequentemente, social. Dessa forma, os funcionários pertencem a uma classe inferiorizada no imaginário social, cuja participação é considerada impossível em função da precariedade da educação recebida por essas pessoas. Assim, estabelece-se a lógica, criticada por Patto (2007), que institui a incompetência daqueles que não detêm o conhecimento científico - único saber valorizado na sociedade moderna. Essa lógica legitima a manutenção da sociedade dividida, uma vez que as únicas pessoas autorizadas a decidir são aquelas que tiveram acesso ao conhecimento científico por meio de sua escolarização formal e, portanto, decidem também em nome de quem não está autorizado.

As psicólogas demonstram o reconhecimento dessa lógica e entendem que o psicólogo tem que atuar junto com os funcionários no sentido de garantir a sua voz no processo associativo, porque esse é um grupo que precisa ter essa participação para que o processo realmente seja democrático. A gestão democrática, como processo em constante construção, necessita de uma atuação cotidiana junto aos funcionários no sentido de realizar sua formação e mediar as relações interpessoais, buscando garantir a sua participação.

\section{d) Atuação das psicólogas escolares juntos às crianças}

Um dos aspectos mais importantes do PPP dessa escola está na concepção de criança que foi construída ao longo dos anos. Essa concepção é fundamentada no respeito à criança, na visão de que ela é uma pessoa que tem desejos e opiniões que precisam ser ouvidos e acolhidos. Contrapõe-se, portanto, à visão de imposição da vontade do adulto, da autorização para que ele fale pela criança, julgando-se mais capaz.

Nas entrevistas e no relato, demonstrou-se, de forma semelhante às elaborações de Larosa (2004) e Castro (2001), uma crítica à escola como instituição de imposição de uma disciplina às crianças, sem a possibilidade de elas falarem sobre o que esperam desse processo educativo. Existe uma busca por uma concepção de educação que parte da compreensão da criança como sujeito, prosseguindo para uma visão semelhante à de Wallon (1952/1987) de que a escola precisa se adaptar ao aluno. É nesse relacionar-se com a criança, conhecê-la, acreditar nela, conversar sobre as suas opiniões, desejos e interesses que um projeto educativo deve ser construído. Nas práticas pedagógicas cotidianas, o conhecimento é sempre trabalhado de forma dinâmica, viva, em constante relação com as questões que surgem dos debates, da experiência com o mundo. Em suma, é um projeto educativo que realiza a construção do PPP também dentro da sala de aula. Esse projeto não está alheio ao que acontece no cotidiano, é pensado e repensado nos vários espaços de debate da associação, nas reuniões de formação continuada dos professores, bem como junto com as crianças em sala de aula. Dessa forma, propicia às crianças a vivência dessa gestão democrática e a sua participação ativa nesse processo.

As falas das psicólogas da Associação demonstram que a sua atuação tem a totalidade do processo educativo como foco; as suas ações são direcionadas a todos os segmentos visando à melhoria da escola como um todo, conforme propunha Wallon (1952/1987). A finalidade da escola é o acesso ao conhecimento formal, de forma ativa, que envolve uma vivência social e um desenvolvimento nas e pelas relações com as pessoas e o conhecimento. O foco está no processo educativo, mas a maneira como ele se constrói também se torna central na atuação desse profissional, que deve valorizar esse processo de construção coletiva como uma forma de realização do ideal que permeia esse PPP, de uma sociedade mais democrática.

\section{Segundo Momento: Escolas Públicas de Educação Infantil do Plano Piloto do DF}

\section{Entrevistas com os Gestores:}

\section{1: O processo de gestão democrática}

À exceção de um, os entrevistados informaram que suas escolas apresentam gestão democrática. Entretanto, esse processo tem se desenvolvido de acordo com concepções bastante diferenciadas. Percebe-se que a ênfase das leis distritais e políticas do governo na efetivação dessa gestão por meio apenas de eleição de diretores e vice-diretores tem sido uma importante influência sobre esse processo nas escolas. Experiências mais democráticas acontecem principalmente independente das determinações do governo a esse respeito e são a minoria. Entretanto, o que se vê na maioria das escolas de Educação Infantil do Plano Piloto é uma centralização de poder nos diretores eleitos e uma redução da atuação dos Conselhos Escolares ao uso das verbas recebidas. Os gestores parecem não reconhecer como sua responsabilidade buscar maneiras diversas de envolver todos os membros da escola nessa construção. 
Quanto à participação dos pais na construção do PPP, a maioria dos gestores afirma que os pais recebem semestralmente um questionário para avaliar o trabalho da escola, porém esses instrumentos não são devolvidos. Dada a falta de procura da comunidade, o corpo docente, juntamente com a direção e coordenação, elabora o PPP com base na avaliação do anterior. Já os funcionários não participam dessa construção. Quando o fazem, suas contribuições tangem a questões mais específicas da sua função. O que fica claro, por fim, é a necessidade de responsabilidade dos gestores, mas também a dos outros membros da escola, na mobilização para a participação efetiva de todos na gestão democrática dessas escolas.

\section{2: Como os gestores percebem a atuação dos psicólogos das EEAAs}

As entrevistas apresentam uma compreensão quase unânime de que o trabalho das EEAAs resume-se à avaliação e ao diagnóstico de alunos com problemas de aprendizagem e de comportamento encaminhados pelos professores. A maioria dos entrevistados afirma que os diagnósticos servem para propor adaptações na escola ou em sala de aula, de acordo com as patologias identificadas nas crianças. Quando questionados sobre se julgavam relevante a contratação de um psicólogo por escola, a maioria respondeu que sim, que seria uma contribuição ao trabalho realizado. Entretanto, pareciam compreender que essa presença traria um acompanhamento mais próximo dos alunos que apresentavam dificuldades e não uma atuação no sentido de melhoria da escola como um todo.

A questão que se sobressai, mesmo numa dita gestão democrática, é o não reconhecimento da possibilidade de atuação do psicólogo nesse processo. Quando questionados se as atuais equipes participam da gestão democrática, a maioria respondeu que não. Ao final das entrevistas, percebe-se que o trabalho do psicólogo junto às escolas é limitado pela sua impossibilidade de participação no seu cotidiano. A quantidade de escolas atendidas impede que ele conheça as pessoas e faça mais intervenções no sentido de adaptar o trabalho pedagógico às necessidades das crianças. Além disso, a sua atuação parece resumir-se àquelas crianças que Ihe são encaminhadas por algum tipo de queixa escolar.

\section{Psicólogas das EEAAs e Coordenadora do SEAA}

\section{1: História do trabalho do psicólogo junto às escolas do DF}

Nas entrevistas e na OP-SEAA, foi possível recuperar a história da atuação do psicólogo nas escolas do DF e suas mudanças ao longo dos anos. Esse trabalho teve origem na década de 60 como uma resposta às demandas relacionadas a alunos que apresentavam dificuldades de aprendizagem ou que recebiam de médicos uma indicação de atendimento especial. Os psicólogos dividiam-se em
Equipes de Avaliação e Diagnóstico, nos Centros de Ensino Especial e em Equipes de Atendimento Psicopedagógico, junto aos alunos da rede regular de ensino. A atuação do psicólogo nessa época estava voltada para a solução de problemas de aprendizagem identificados nos alunos por meio de atendimento com a função de ajustamento para que pudessem voltar à sala de aula. Englobava orientações aos pais e encaminhamentos a médicos com base em uma visão de que os problemas eram dos alunos e a intervenção junto a eles encerraria esses problemas. Caso o atendimento psicopedagógico não surtisse efeito, ou houvesse suspeita de deficiência, eles eram encaminhados para as equipes do Ensino Especial. Em 2004, dado o processo de inclusão nas escolas do DF, houve a fusão dessas equipes, primeiramente denominadas Equipes de Atendimento e Apoio à Aprendizagem, tendo a partir de 2006 esse nome modificado para $o$ atual, EEAA.

\section{2: Diretrizes atuais sobre o trabalho das EEAAs: a proposta institucional}

As EEAAs são compostas por um psicólogo e um pedagogo, porém eventualmente contam apenas com um pedagogo. Faltam concursos para psicólogos e, consequentemente, a maioria dos profissionais que ocupam esses cargos caracteriza-se por desvio de função, ou seja, são professores que, ao se formarem como psicólogos, passam a trabalhar nas EEAAs. Na OP-SEAA percebe-se uma crítica à atuação restrita ao processo avaliativo e diagnóstico. Esse documento demonstra a ampliação das ações das equipes por meio da sua atuação preventiva e institucional, que envolve três grandes dimensões: o Mapeamento Institucional, a assessoria ao trabalho coletivo dos professores e o acompanhamento do processo ensino-aprendizagem.

Entretanto, percebe-se, na entrevista da Coordenadora do SEAA, que, ao mencionar essa ampliação, seu foco ainda está nos alunos e no entendimento de que suas dificuldades de aprendizagem Ihes são inerentes. Ela faz referência a diagnósticos de problemas no desenvolvimento, como "discalculia" ou TDAH. Essa noção parece assemeIhar-se àquela proposta por Novaes (1980) em que, a partir de um determinado diagnóstico sobre o problema do aluno, são desenhadas estratégias de ensino para superar esses problemas. Assim, demonstra a possibilidade de realizar mudanças no ensino de acordo com as necessidades da criança, porém essas mudanças são feitas para os casos considerados desviantes, demonstrando uma compreensão de normalidade no desenvolvimento humano, em detrimento de uma visão da diversidade como algo que traz o dinamismo para o fazer educativo. Dessa forma, as demandas dos alunos são vistas como patologias, ao invés de questões que podem ser aproveitadas para tornar o ensino mais plural e vivo.

Retomando a crítica, comum na produção em psicologia escolar, quanto ao modelo clínico de atuação, o trabalho das psicólogas entrevistadas parece ainda não superar os problemas apontados. Está, até certo ponto, ainda baseado 
na lógica excludente de que os problemas são das crianças e não de um sistema escolar estático e voltado para a normalidade. Os conflitos não são vistos como contribuições ao desenvolvimento de uma educação de qualidade, como aquele encontrado na associação, mas sim como situações que devem ser prevenidas, portanto evitadas por serem consideradas desajustes e exceções. A concepção das entrevistadas sobre a perspectiva institucional não parece se traduzir em intervenções na melhoria das escolas, mas sim do rendimento dos alunos.

\section{3: O trabalho realizado pelas psicólogas nas EEAAs}

As entrevistas demonstram o excesso de trabalho das equipes que, ao atender várias escolas, não conseguem responder à demanda, muito menos conhecer a realidade de cada uma delas. A questão da chamada "estratégia de matrícula" é uma das principais queixas das psicólogas em relação ao excesso de trabalho. Essa "estratégia de matrícula" refere-se ao trabalho das equipes na configuração de rearranjos em sala de aula a partir dos casos de crianças com algum tipo de diagnóstico formalizado. Assim, uma função que toma muito tempo das equipes é avaliar os alunos encaminhados por alguma dificuldade, realizar o diagnóstico e a partir disso indicar adaptações para cada caso. Essas adaptações vão desde redução do número de alunos por turma até a solicitação de um monitor para o acompanhamento individual desse aluno em sala.

Percebe-se a falta de clareza sobre a chamada atuação institucional. Ora entende-se como a realização de atividades informativas, como oficinas e palestras, junto aos pais e aos professores sobre questões do desenvolvimento psicológico das crianças, ora como uma capacitação do professor para que resolva os seus problemas, com o suporte e orientação da equipe. Compreende-se que essa atuação não consiste em retirar o aluno de sala para fazer atendimento, porque isso seria atendimento clínico, o que não pode mais ser feito nas escolas. Todos esses entendimentos não contemplam uma atuação do psicólogo no cotidiano da escola no sentido de fazer intervenções para repensar o PPP.

A partir dessas entrevistas, nota-se que o excesso de demandas às EEAAs impossibilita que suas intervenções tragam contribuições ao projeto educativo realizado. A busca por superar o chamado modelo clínico não tem rompido com o ideal de classificação e segregação dos alunos que fundamenta esse modelo. A tentativa de ampliar o leque de atuação das EEAAs ainda mantém a lógica de patologização dos problemas escolares e a visão de que, se um aluno apresenta alguma dificuldade, então o problema está nele.

\section{4: O trabalho do psicólogo nas EEAAs em relação à gestão democrática}

As entrevistadas não mencionam a possibilidade de um trabalho nas relações interpessoais da escola, nem na contribuição do PPP. Parecem entender que ter um psicólogo por escola, ou uma equipe por escola, seria a possibilidade de realizar uma avaliação mais célere e tentar intervir melhor junto aos professores. A OP-SEAA tenta criar bases para uma atuação das equipes mais próxima às escolas, sem se resumir à avaliação de problemas. Porém, não compreendemos como essa proposta pode se materializar se as equipes são consideradas um apêndice às escolas, ao contrário de serem uma parte do seu quadro funcional. Se o psicólogo não está presente na escola, no seu cotidiano, não enxerga a possibilidade de transformação e construção permanente do PPP por meio do seu trabalho. Não tem como atuar de modo que a escola atenda às necessidades de cada criança e aos objetivos de seus profissionais e da comunidade quanto ao projeto educativo realizado. Percebemos que as mudanças realizadas no SEAA foram no sentido de alterar o nome e o foco de atuação dessas equipes, porém a configuração enquanto equipes isoladas permanece. Entendemos, entretanto, que a única forma de desenvolver um trabalho que rompa com modelos de atuação segregacionistas, voltados para o ajustamento e a adaptação dos alunos ao sistema escolar vigente, é fazer parte do cotidiano da escola, trabalhando em conjunto com todos os seus membros no processo de gestão democrática a fim de consolidar uma educação de qualidade, viva e plural. Quanto ao distanciamento do psicólogo em relação à equipe pedagógica, assim como foi possível observar nas entrevistas com os gestores, as entrevistadas ressaltam conflitos na atuação junto aos professores.

A partir das informações obtidas com este estudo, observa-se que a psicologia escolar vem desenvolvendo um trabalho avaliativo e diagnóstico, coerente com um sistema educacional segregacionista e voltado para uma suposta normalidade de desenvolvimento humano. Não é à toa, portanto, que ainda seja difícil construir junto às escolas uma nova forma de atuação, ainda mais considerando as incoerências e contradições presentes nas entrevistas dos membros das escolas públicas. Evidencia-se, portanto, o quanto o contexto democrático impacta o trabalho do psicólogo escolar. Esse fato demonstra a necessidade de repensar o sistema educativo como um todo e os pressupostos filosóficos e ideológicos que o fundamentam. O psicólogo escolar deve denunciar essa ideologia segregacionista e adaptacionista, buscando modificar, juntamente com os outros membros da escola, os objetivos de uma educação democrática.

\section{Considerações Finais}

Neste estudo, tivemos por objetivo construir uma proposta de atuação do psicólogo escolar para a gestão democrática nas escolas públicas de Educação Infantil do Plano Piloto do DF (Chagas, 2010). Esse objetivo surgiu do nosso compromisso com uma educação pública de qualidade, entendendo que esta só pode se realizar com a participação de toda a comunidade escolar na construção dos projetos político pedagógicos das escolas. É importante ressaltar que 
não pretendemos oferecer um modelo de atuação em psicologia escolar pronto, aplicável a qualquer contexto. Pelo contrário, entendemos que cada contexto escolar, dada a sua diversidade e complexidade, demanda ações que the são próprias, construídas junto com os seus participantes. Transformar este estudo em um manual descritivo de ações do psicólogo escolar seria sabotar a nossa intenção de criar uma atuação para a gestão democrática. Primeiro, porque um manual eliminaria a autonomia do psicólogo de construir uma atuação própria a partir da sua análise de cada escola e da sua relação com os seus membros. Segundo, porque a atuação para a gestão democrática demanda um olhar para a realidade da escola, para as necessidades de cada sujeito e do grupo.

Propomos que o psicólogo escolar, a partir de uma formação teórico-prática fundamentada na psicologia materialista dialética, contribua com a sua especificidade à gestão democrática ao oferecer um olhar diferenciado para a singularidade dos sujeitos, uma compreensão da diversidade do desenvolvimento humano, uma escuta dos não ditos presentes nas falas das pessoas e uma atuação na mediação das relações interpessoais. A sua atuação se direciona, assim, para a melhoria da escola como um todo, não apenas focado em um aspecto ou um segmento desse contexto. Dessa forma, pode auxiliar na compreensão dos fenômenos psíquicos no contexto escolar de maneira abrangente, reconhecendo a necessidade da construção coletiva em prol de uma educação de qualidade para todos.

Essa proposta, voltada para a Educação Infantil, fundamenta-se na ideia de que acolher a diversidade e a novidade infantil é trazer possibilidades tanto para uma educação mais autônoma e respeitosa dos direitos da criança, quanto para a transformação da sociedade pela novidade trazida. Nesse sentido, concebemos a Educação Infantil como um espaço de acesso ativo ao conhecimento formal produzido por uma sociedade, em que crianças e professores são parceiros na exploração do mundo a partir da sua curiosidade e de seus interesses. As crianças não são um receptáculo dos conteúdos que os adultos julgam necessários para a sua formação, mas sim participativas na construção do projeto de educação. O professor é um organizador do meio social, que não se impõe às crianças, mas tem a responsabilidade de proporcionar práticas educativas que tanto façam sentido para seus alunos, quanto despertem novos interesses pela construção de conhecimento.

Dessa forma, entendemos que a participação de todos os membros da escola na gestão democrática é essencial para a melhoria da sua qualidade. Vale ressaltar que essa forma de gestão não é concebida apenas como a eleição de diretores, vice-diretores e representantes de cada segmento no Conselho Escolar. Ela demanda a construção e a implementação do PPP da escola por todos os seus membros no seu cotidiano, desde a sala de aula até os espaços de reunião da comunidade escolar, passando pelas conversas de corredor e pelo bate-papo na hora do cafezinho. É o exercício democrático diário, a convivência em comunidade e o diálogo plural e diverso em vários espaços da escola que constroem a gestão democrática da escola.

O objetivo da proposta apresentada foi demonstrar a nossa visão de que a atuação do psicólogo na gestão democrática tanto é contribuir para a efetivação de direitos estabelecidos na Constituição e na LDB, quanto uma possibilidade de a psicologia escolar superar modelos de atuação classificatórios e segregacionistas que legitimam uma educação ideologizada e mantenedora do status quo. Uma psicologia comprometida com a construção de uma sociedade democrática que garanta os direitos dos seus cidadãos direitos esses construídos em lutas históricas por melhores condições sociais - precisa posicionar-se na luta por uma escola menos excludente e mais democrática. Esse posicionamento passa pela defesa da gestão democrática. Dessa forma, a nossa proposta baseia-se muito mais em princípios e compromissos com esses direitos do que em receitas de como agir em qualquer escola.

\section{Referências}

Andaló, C. S. A. (1984). O papel do psicólogo escolar. Psicologia, ciência e profissão,_1, 43-47.

Barreto, M. S. V. (2007). A formação continuada de gestores escolares em dois municípios mineiros: do PROCAD ao PROGESTÃO. Dissertação de Mestrado, Universidade de Brasília, Brasília, DF.

Castro, L. R. (2001). Da invisibilidade à ação: crianças e jovens na construção da cultura. Em L. R. Castro (Org.), Crianças e jovens na construção da cultura (pp. 19-46). Rio de Janeiro: NAU, São Paulo: FAPESP.

Chagas, J. C. (2010). Psicologia escolar e Gestão Democrática: uma proposta de atuação em escolas públicas de Educação Infantil. Dissertação de Mestrado, Universidade de Brasília, Brasília, DF.

Constituição da República Federativa do Brasil. (1988). Brasília, DF.

Freire, P. (2000). À sombra desta mangueira. São Paulo: Olho D'água

Larosa, J. (2004). Pedagogia Profana: danças piruetas e mascaradas. Belo Horizonte: Autêntica.

Lei n. 9.394. (1996). Estabelece as Diretrizes e Bases da Educação Nacional. Diário Oficial da União, seção 1.

Meira, M. E. M. (2003). Construindo uma concepção crítica de psicologia escolar: contribuições da pedagogia histórico-crítica e da psicologia sócio-histórica. Em M. E. M. Meira \& M. A. M. Antunes (Orgs.), Psicologia escolar: teorias críticas (pp. 13-77). São Paulo: Casa do Psicólogo.

Novaes, M. H. (1980). Psicologia Escolar. Petrópolis, RJ: Vozes.

Orientação Pedagógica: Serviço Especializado de Apoio à 
Aprendizagem. (2010). Secretaria de Estado de Educação do Distrito Federal. Brasília, DF.

Patto, M. H. S. (1987). Psicologia e ideologia: uma introdução crítica à psicologia escolar. São Paulo: T. A. Queiroz.

Patto, M. H. S. (2007). A psicologia em questão. Em M. H. S. Patto \& J. A. F. Pereira (Orgs.), Pensamento cruel - humanidades e ciências humanas: há lugar para a psicologia? (pp. 3-15). São Paulo: Casa do Psicólogo.

Pedroza, R. L. S. (2003). A psicologia na formação do professor: uma pesquisa sobre o desenvolvimento pessoal de professores do ensino fundamental. Tese de Doutorado, Universidade de Brasília, Brasília, DF.

Peixoto, E.M. (2009). Políticas de educação profissional e tecnológica: a influência dos princípios de gestão democrática nas deliberações do CEFET-MG. Dissertação de Mestrado, Universidade de Brasília, Brasília, DF.

Pulino, L. H. C. Z. (2001). Gestão democrática da instituição de Educação Infantil: a experiência da "Vivendo e Aprendendo". Em Aberto, 18(73), 131-135.
Souza, M. P. R. (2009). Psicologia escolar e educacional em busca de novas perspectivas. Psicologia Escolar e Educacional, 13(1), 179-182.

Vigotski, L. S. (2000). Obras Escogidas (Volume III). Madrid: Visor. (Trabalho original publicado em 1931)

Wallon, H. (1975). Objectivos e métodos da psicologia. Lisboa: Editorial Estampa. (Trabalho original publicado em 1951)

Wallon, H. (1979). Psicologia e educação da criança. Lisboa: Editorial Vega. (Trabalho original publicado em 1937)

Wallon, H. (1987). Por que los psicologos escolares? Em J. Palacios (Org.), Psicología y educación del niño: una comprensión dialéctica del desarrollo y la educación infantil (pp. 301-303). Madrid: Visor Libros. (Trabalho original publicado em 1952)

Recebido em: 11/11/11

Reformulado em: 13/02/12

Aprovado em: 03/09/12

\section{Sobre as autoras}

Julia Chamusca Chagas (juliacchagas@gmail.com)

Universidade de Brasília - Mestre em Processos de Desenvolvimento Humano e Saúde.

Endereço: Av. Parque Águas Claras, 2675 Bloco-A apto-806 Ed. Morada do Parque, Águas Claras - Brasília (DF) - 71.906-500

Regina Lúcia Sucupira Pedroza (rpedroza@unb.br)

Universidade de Brasília - Doutora em Psicologia.

Endereço: Colina Bloco-H apto-302, Asa Norte - Brasília (DF) - 70.910-900

Este artigo foi produzido a partir da Dissertação de Mestrado intitulada "Psicologia Escolar e Gestão Democrática: uma proposta de atuação em escolas públicas de Educação Infantil” apresentada por Julia Chamusca Chagas, sob a orientação da Profa. Dra. Regina Lúcia Sucupira Pedroza, ao Instituto de Psicologia da Universidade de Brasília, como requisito parcial à obtenção do título de Mestre em Processos de Desenvolvimento Humano e Saúde, na área de Desenvolvimento Humano e Educação. Esse trabalho contou com o apoio financeiro da Coordenação de Aperfeiçoamento de Pessoal de Nível Superior - CAPES. 
